\title{
Sudoeste Paranaense: Desmatamento como Estratégia de Posse da Terra (1940-1960)
}

\author{
Ismael Antônio Vannini ${ }^{1}$, Rodrigo Kummer ${ }^{2}$
}

\begin{abstract}
RESUMO
O artigo apresenta uma abordagem referente ao processo de ocupação e colonização do Sudoeste do Paraná. Ocupada pelo deslocamento das correntes migratórias internas, ocorrido entre 1940 e 1960, a região que concentrava a maior floresta de araucárias do planeta, foi profundamente transformada pela ação do governo, pelas companhias imobiliárias e pelos colonos posseiros. Ações litigiosas entre o governo do Estado e da União impediam a lavratura da escritura pública dos lotes e os colonos assentados tornaram-se posseiros. O desmatamento transformou-se na estratégia dos colonos para delimitar sua posse. Como resultado, os estudos apontam que $80 \%$ da vasta floresta de pinheirais transformaram-se em cinzas. Assim, a História Ambiental do Sudoeste paranaense apresenta elementos diretos da política governamental e da ação humana ligada à posse da terra.
\end{abstract}

Palavras-Chave: Sudoeste paranaense; Desmatamento; História Ambiental.

\footnotetext{
${ }^{1}$ Doutorado pela Pontifícia Universidade Católica do Rio Grande do Sul - PUCRS, Pós-Doutorado pela Universidade Federal do Paraná - UFPR. Docente da Universidade Estadual do Centro-Oeste do Paraná - UNICENTRO. Email: vaniniunicentro@gmail.br

${ }^{2}$ Mestre em Ciências Sociais pela Universidade Estadual do Oeste do Paraná - UNIOESTE, Doutorando do Programa de Pós-Graduação de Ciências Sociais em Desenvolvimento, Agricultura e Sociedade - Universidade Federal do Rio de Janeiro - CPDA/UFRRJ.
} 


\section{INTRODUÇÃO}

A região Sudoeste paranaense se caracteriza por um processo conflitivo de organização e de ocupação do espaço. Estabeleceu-se como parte da estratégia de colonização oficial organizada a partir dos interesses da União e do capital agrário. Invizibilizou-se a existência de indígenas e caboclos no território, bem como sua historicidade e cultura. A introdução de colonos brancos, ou "de origem ${ }^{3 ",}$ reorganizou um espaço dominado por "brasileiros" ${ }^{4 "}$ e fortaleceu um discurso de desenvolvimento e progresso num espaço dito "vazio".

Esses núcleos fundadores oficiais originaram-se a partir da década de 1940 e o processo de ocupação territorial se acentuou na década seguinte. Ainda incipiente, a historiografia dá os primeiros passos em estudos mais sistematizados no sentido de historicizar a região. Alguns estudos pioneiros deram conta de apontar e narrar os acontecimentos históricos e, na última década, pesquisas desenvolvidas nos programas de pós-graduação de diferentes universidades obtiveram avanço maior por conta da sistematização.

Mesmo que modesta, no que tange avançar na historiografia da região, entende-se como oportuna uma abordagem no âmbito da História Ambiental. Tratando-se de uma região que concentrava a maior floresta de araucárias do planeta, no conjunto de ecossistema rico e extenso, a temática ambiental assume importância destacada para a compreensão da relação homem e natureza.

Um conjunto de fatores contribuíram para a ação humana no ambiente da região em questão. Os limites de fronteira, contestados e disputados entre o Brasil e Argentina, incitaram uma política expansionista do governo federal para o Oeste brasileiro e do Paraná, em especial. A ação governamental contribuiu de forma decisiva ao criar as colônias de ocupação e subsidiar o assentamento das correntes migratórias. Ligado a este fator, o longo processo litigioso e de embargos da titulação fundiária das terras da região - que causou incertezas no sentido de legitimação da

\footnotetext{
${ }^{3}$ Arlene Renk, A luta da erva: um ofício étnico no Oeste Catarinense, (2. ed. rev. Chapecó: Argos, 2006).

${ }^{4}$ Como aponta Arlene Renk (Ibid), a população não definida pela imigração ou ascendência europeia era identificada como brasileira, numa perspectiva de depreciação.
} 
propriedade - incitou o caráter da posse precária através da demonstração da presença humana. Ou seja, o desmatamento.

Os grupos humanos que migraram para a região representaram a extensão étnica e cultural das antigas regiões de imigração sulista. Carregavam consigo o ideal da propriedade privada da terra e a viabilização econômica e policultura de caráter familiar. Uma cultura que ensejava, como visão civilizadora e de progresso, transformar o ambiente "selvagem" para a produção de víveres e riquezas. Imbuídos por este ideal, e com o incentivo governamental, a transformação no ambiente seria uma necessidade e uma prática imediata.

O texto se estrutura inicialmente com breves apontamentos teóricos e metodológicos como referência norteadora da temática da historiografia ambiental. O histórico litigioso das terras do Sudoeste, que vem a seguir, propõe identificar a ação governamental desde o período imperial até a criação da colônia agrícola de colonização no governo Vargas, no início da década de 1940. O fenômeno da migração e a ação humana como ocupação estratégica de posse da terra complementam a análise.

\section{APONTAMENTOS PARA HiSTÓRIA AMBIENTAL}

Os estudos sistemáticos na temática da História Ambiental avançaram, sobretudo, a partir da década de 1970, incitados pela crise do ambiente global e pelos movimentos ambientalistas. Surgiu em uma época de renovação e reavaliação cultural mais ampla. Iniciados pela comunidade científica norte americana, institucionalizaram-se em diferentes países, na proposta de avançar com a historiografia para além da História Política, Econômica, Social e Cultural. A premissa

\footnotetext{
${ }^{5} \mathrm{O}$ projeto idealizado pelo governo adotara um discurso que a ocupação se daria em um espaço vazio e de caráter selvagem, desconsiderando a presença de comunidades nativas e caboclas que habitavam o espaço. Presentes na região, os Kaingang e Xokleng viviam como caçadores e coletores, dividindo o espaço com a comunidade cabocla, que se valiam da extração subsistente dos ervais nativos. Estes grupos perderam o território diante do avanço colonizador. O grupo indígena foi reduzido nas reservas da região, enquanto o caboclo foi pressionado a buscar outro espaço, disseminando-se pelo território, e aos poucos, foi incorporando de forma excludente no modus vivendi do colonizador.
} 
da História Ambiental procura romper a ideia convencional de que a experiência humana teria se desenvolvido sem restrições naturais. ${ }^{6}$

A História Ambiental se originou por um objetivo moral, depois que o interesse e a preocupação popular com o ambiente já haviam começado a decair. Depois disso, foram surgindo os compromissos políticos e amadurecendo para o interesse acadêmico, com a proposta de ir além de uma agenda moral e política. Seu objetivo principal norteou-se em aprofundar o entendimento de como os seres humanos foram, através dos tempos, afetados pelo seu ambiente natural, e, inversamente, como eles afetaram este ambiente e com que resultados. ${ }^{7}$

Os movimentos ambientalistas intensificados na segunda metade do século XX promoveram e exigiram que as diferentes áreas do conhecimento tratassem, com estudos de caráter acadêmico, a temática relacionada ao ambiente. Assim como a História, o Direito, a Filosofia, a Economia a Sociologia e outras se tornaram sensíveis com a causa. O movimento e a voz das ruas tiveram importância na formalização da História Ambiental.

Como um dos grandes centros de vanguarda e produção da Nova História, as universidades Norte Americanas, representam, também, as preocupações ambientais daquele país. Os pioneiros pesquisadores da História Ambiental definem que a paisagem que rodeia o homem é um documento. Seguindo na mesma ótica, a França tornou-se outro centro inovador, especialmente os historiadores ligados à revista dos Annales, que por várias décadas se dedicam ao tema do ambiente. A revista reitera o princípio de que a História Ambiental reúne os temas mais antigos com os mais recentes da historiografia contemporânea. Reconhecem a evolução das epidemias e do clima, fatores que são partes integrantes do ecossistema humano. ${ }^{8}$

\footnotetext{
${ }^{6}$ Cf. José Augusto Pádua, "As bases teóricas da História Ambiental", in Estudos Avançados, 68, (2010), p. 81-101.

${ }^{7}$ Cf. Donald Worster, "Para Fazer História ambiental" in Estudos Históricos, 8, (1991), p. 198-215.

8 lbid.
} 
A abordagem ambiental no Brasil, por sua vez, está pautada por inúmeros fatores que ensejam os temas para a historiografia. ${ }^{9}$ A grandeza territorial do país é constituída com variações marcantes nos processos ecológicos, nos ecossistemas e nas paisagens, com palcos distintos de interações entre as sociedades humanas e a natureza. De clima quente, comporta uma grande biodiversidade e engloba comunidades biológicas, formações litorâneas e formas de vida marinhas e oceânicas. A especificidades da ocupação do território brasileiro contribuem para a construção de discurso de que há, aqui, um espaço com biodiversidade e paisagem menos alteradas que no "Velho Mundo".

É evidente, portanto, o crescimento da importância dos estudos históricos que têm como objeto de base o meio ambiente para compreender os novos problemas relacionados à construção dos processos de interação social. Estes estudos focam-se no reordenamento e na religação de saberes e desconstroem a dicotomia natureza/cultura, reafirmando sua sensível e dramática inerência.

De forma geral, a historiografia ambiental articula uma abordagem entre o tempo natural, ou geológico e o tempo social. Propõe relacionar as escalas do tempo da Geologia e da Biologia contadas como tempo longo e o tempo curto dos processos humanos; em outras palavras, a relação entre homem e natureza ao longo do tempo. Sendo que por "natureza" a maior parte dos historiadores ambientais compreende todo o mundo não-humano ou não-criado originalmente pelo homem. Nesta legenda, se insere uma especialidade que engloba uma vasta gama de discussões e problemáticas em uma série de diálogos interdisciplinares, pouco comuns para os estudos das Ciências Humanas. Trata-se de uma aproximação com o conjunto das chamadas Ciências Naturais e Exatas.

Estudos importantes das Ciências da Natureza já foram realizados no Sudoeste paranaense, bem como pesquisas acadêmicas desenvolvidas no interior dos

\footnotetext{
${ }^{9}$ Apesar de alguns autores tratarem, em período anterior, a relação entre homem e natureza, como Capistrano de Abreu, Sérgio Buarque de Holanda, Caio Prado Jr. Gilberto Freire, Josué de Castro e Darcy Ribeiro, entre outros, a historiografia brasileira muito recentemente direcionou-se para o tema restrito da História Ambiental. Podem ser citados também os trabalhos de Warren Dean: "A luta pela borracha no Brasil: um estudo de história ecológica" (1989) e "A ferro e fogo: história e devastação da Mata Atlântica brasileira" (1996); de José Augusto Drummond: "Devastação e preservação ambiental: os parques nacionais do Estado do Rio de Janeiro" (1997); de Victor Leonardi: "Entre árvores e esquecimentos: História social nos sertões do Brasil" (1996) e "Os historiadores e os rios: natureza e ruína na Amazônia brasileira" (1999); e de Paulo Bertran: "História da terra e do homem no Planalto Central: eco-história do Distrito Federal: do indígena ao colonizador" (1994).
} 
programas de pós-graduação, sobretudo na área da Geografia e Biologia. Tais estudos identificam o processo de devastação da maior floresta de araucária do planeta, promovida pelo avanço do elemento étnico colonizador. A abertura de áreas agricultáveis, associada ao processo de urbanização, promoveu grande alteração e degradação do ambiente natural.

Apesar de a ocupação territorial e a consequente intervenção no ambiente constituírem-se em fenômeno tendencialmente comum a todas as frentes de colonização, o olhar e o viés da História Ambiental vem elucidar os fatores de ordem política, econômica, social e cultural que também influíram na ação humana sobre o ambiente natural do Sudoeste paranaense.

\section{HISTÓRICO LITIGIOSO DAS TERRAS DO SUDOESTE DO PARANÁ}

A região foi tomada como interesse estatal a partir da "descoberta" dos Campos de Guarapuava em 1770 e mais tarde dos Campos de Palmas em 1837. A área era importante sob muitos aspectos: para a expansão das atividades agropastoris; como via de acesso aos campos de criação de gado do Rio Grande do Sul e como domínio de territórios em litígio com a Argentina. Além do litígio transnacional, a região era palco de um conflito com as populações indígenas. Desde a chegada da Família Real no Brasil em 1808, iniciou-se um enfrentamento oficial aos grupos indígenas que não "colaboravam" com os interesses da Coroa. Na Carta Régia de 5 de novembro de 1808 ordenou-se o ataque a essas populações. Em 1810 os Kaingang foram vencidos, subjugados e divididos para estimular uma rivalidade interna. De um lado estavam os "camés" e de outro os "votorões". ${ }^{10}$ Os grupos Xokleng, mais arredios ao contato, foram sendo sumariamente dizimados.

A criação da freguesia de Palmas (1855) expressou a articulação do Império brasileiro para garantir o controle desse território: "a economia pastoril reclamava novos campos para sua expansão e a geopolítica do império seguia as linhas mestras

\footnotetext{
${ }^{10}$ Cf. Wilmar da Rocha D’Angelis, "Para uma história dos índios no Oeste catarinense", Cadernos do CEOM: 20 anos de memórias e histórias no oeste de Santa Catarina, ano 19, n. 23, (2006). p. 265-346.
} 
da estratégia de ocupação portuguesa"." Além do domínio sobre os indígenas, estimulou-se a entrada de escravos africanos para o trabalho nas fazendas de gado. ${ }^{12}$ Essa relação potencializou a abertura de caminhos na região, seguindo o caminho Norte - Sul (Palmas - Xapecó - Nonoaí - Cruz Alta). Eram rotas importantes para as tropas, para o intercâmbio comercial e para a própria defesa e conquista do território pela nação.

Já nesse período (meados do século XIX), os interesses argentinos na região aumentavam, exatamente devido à exploração madeireira que iniciavam usando o curso do Rio Uruguai e à exploração ervateira, então em fraca expansão. Daí reacender-se, nesse momento, o litígio sobre os limites internacionais naquela zona, reivindicando a Argentina o território de Missiones (disputado ao Paraguai) e as terras situadas a Oeste dos rios Chapecó e Chopin (disputadas ao Brasil). A ocupação efetiva do território torna-se, então, questão estratégica para a geopolítica do Império. Nesse contexto é que a abertura da estrada de Palmas a Corrientes torna-se inadiável. Os planos brasileiros previam, certamente, estabelecer uma situação de fato que lhe favorecesse na decisão do litígio, e preparar a ocupação definitiva (com povoações), quando essa decisão ocorresse. ${ }^{13}$

Com a criação da Província do Paraná em 1853, os Campos de Palmas passaram à jurisdição paranaense. O Estado do Paraná iniciou a expedição de títulos de propriedade e foram favorecidos os correligionários políticos de Curitiba, Guarapuava e de Palmas. Mais tarde, no início do século XX, estes títulos e essas terras estiveram no epicentro do confronto da Guerra do Contestado (1912-1916).

Outra estratégia de ocupação oficial do território foi expressa com a criação de duas colônias militares na região. As Colônias Militares do Chapecó e Chopim instituídas pelo decreto $\mathrm{n}^{\circ} 2502$, de 16 de novembro de 1859 - tinham como interesse facilitar o alojamento populações nacionais no território em disputa, além de proteger as vilas e fazendas já existentes. A ameaça, nesse caso, não vinha apenas dos argentinos, mas também dos indígenas. A presença das colônias, como indica D’Angelis $^{14}$, acelerou a entrada de agricultores e pecuaristas na região, ainda que estivessem situados na porção não contestada do território envolvido diretamente na

\footnotetext{
${ }^{11}$ lbid, 282.

12 Cf. José Lúcio da Silva Machado, O Sertão e o Cativo. Escravidão e Pastoreio: Os campos de Palmas-Paraná 1859-1888, (Porto Alegre: Coleção Malungo-FCM Editora, 2015).

13 Wilmar da Rocha D'Angelis, "Para uma história dos índios no Oeste catarinense", Cadernos do CEOM: 20 anos de memórias e histórias no oeste de Santa Catarina, ano 19, n. 23, (2006). p. 265-346, 293.

${ }^{14}$ Ibid.
} 
"Questão de Palmas". Segundo Vera Fregonese, "as unidades passaram a desenvolver atividades que além de visarem a colonização e o povoamento propriamente ditos, preocupavam-se com a defesa e a proteção das áreas consideradas estratégicas". ${ }^{15}$

Questões de limites de fronteira ${ }^{16}$ sempre foram preocupações do governo nacional. Na região Sudoeste impactou diretamente a Questão de Palmas, ou Questão de Missiones, que foi um litígio territorial inicialmente entre Espanha e Portugal e depois entre Argentina e Brasil. Se estendeu desde o Tratado de Santo Ildefonso (1777) até o arbitramento internacional em 1895 com ganho de causa em favor do Brasil. A área configura boa parte dos atuais Oeste catarinense e Sudoeste paranaense e era considerada, na época, estratégica para o Brasil do ponto de vista da defesa e soberania nacional. A forma de assegurar o domínio deste espaço era garantir a ocupação, para então obter o direito por meio do princípio de direito romano do uti possidetis. $^{17}$

As questões ligadas à posse da terra no Sudoeste do Paraná remetem, portanto, ainda ao período do Império brasileiro. Além de serem estratégicas para os interesses geopolíticos, forma acionadas como ativos para a construção de obras públicas, principalmente ferrovias. Ainda em 10 de novembro de 1889, D. Pedro II concedeu, via decreto, uma faixa de terras de nove quilômetros em cada lado da linha férrea Itararé-Uruguai. O governo da República manteve o decreto imperial, com algumas simples alterações. Em 1893, estas concessões foram transferidas, também por decreto, para a Companhia Estrada de Ferro São Paulo-Rio Grande, do grupo Brazil Railway Company. ${ }^{18}$

No entanto, pela constituição da República de 1891, as glebas de terras devolutas passaram ao domínio dos Estados. Em novo contrato de 1920, o Estado do Paraná concedeu uma área de aproximadamente 2.100.000 hectares à São Paulo-Rio

\footnotetext{
${ }^{15}$ Vera Lúcia Fregonese, "Experiência de colonização: Colônia Militar do Chopin", in História: construção de múltiplas interfaces, Carlos Antônio Bonamigo (Francisco Beltrão: Grafisul, 2006), 195.

${ }^{16}$ Vale lembrar da existência de ampla e rica literatura tratando questões de fronteira e limites entre o Brasil e os países platinos. Apesar de não aprofundadas neste ensaio, precisam ser consideradas como fenômeno reminiscente a ocupação da região Sudoeste do Paraná. Ou seja, as terras "desocupadas" ou devolutas nas regiões de fronteira, recorrentemente entravam em questões de litígio, precisavam ser integradas ao modelo vigente e aos moldes do sistema.

${ }^{17}$ Cf. Adelar Heinsfeld, A questão de Palmas entre Brasil e Argentina, (Joaçaba: Ed. UNOESC, 1999).

${ }^{18}$ Cf. Iria Zanoni Gomes, 1957, a Revolta dos Posseiros, (Curitiba: Criar Edições, 2005).
} 
Grande para a construção de um ramal ferroviário que ligava Guarapuava com a Itararé-Uruguai. Nesta transação foram usadas como moeda de pagamento as glebas Santa Maria, Silva Jardim, Riosinho e Missões, que ficava no Sudoeste do Estado do Paraná $^{19}$, conforme apresentado na Figura 1.

Figura 1: Mapa de delimitação das antigas glebas da região Sudoeste do Paraná

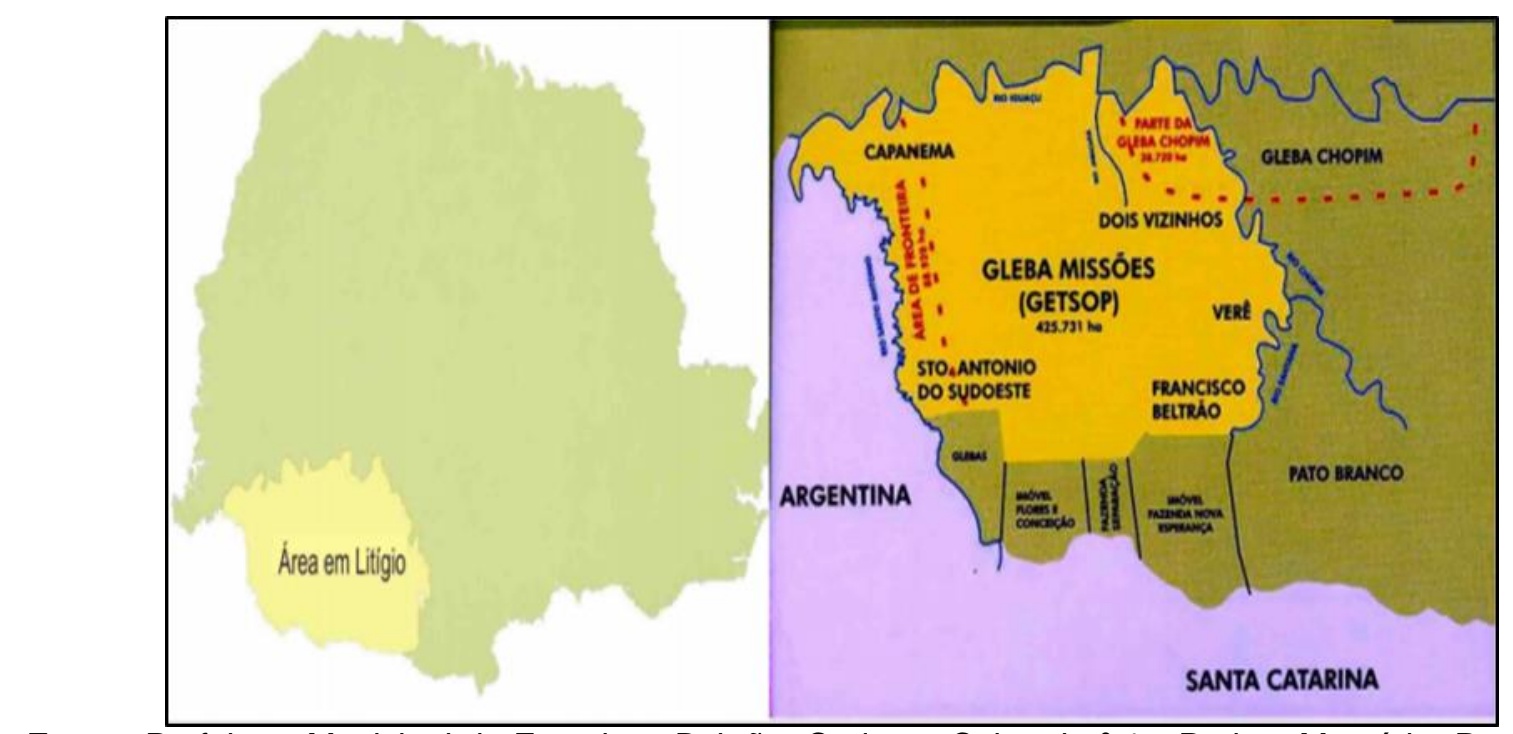

Fonte: Prefeitura Municipal de Francisco Beltrão. Caderno Cultural ํㅜ 1 - Projeto Memória: Revolta dos Posseiros: Cinquentenário 1957-2007.

A construção dessa ferrovia desencadeou a Guerra do Contestado (1912-1916), visto que as terras concedidas estavam ocupadas por populações indígenas e caboclas. Esses posseiros históricos foram desalojados e ao resistirem foram massacrados pelas forças federais, embora comodamente a companhia construtora e os grandes fazendeiros tiveram seus interesses preservados. Com um saldo de milhares de mortes a guerra representou uma "limpeza étnica" e facilitou o ingresso dos colonos. A contestação, nesse caso, foi reconhecida apenas como um litígio territorial entre o Estado de Santa Catarina e o Estado do Paraná que lutavam, desde a Proclamação da República, pelo controle da região. Em 1917 o governo federal definiu

${ }^{19}$ Cf. Iria Zanoni Gomes, 1957, a Revolta dos Posseiros, (Curitiba: Criar Edições, 2005). 
a partilha ou divisão da área em disputa. E a partir daí as Unidades da Federação aceleraram seus projetos de colonização. ${ }^{20}$

As concessões de terra, porém, esbarravam na burocracia, nos interesses privados e nos vários documentos anteriormente expedidos pela União e pelos Estados. No caso da ferrovia São Paulo-Rio Grande, em julho de 1940, a União reincorporou os bens cedidos à Brazil Railway Company, alegando questões legais e morais, sobretudo pela grande dívida e sonegação tributária. Para administrar as glebas e bens incorporados, o governo federal criou a SEIPAN - Superintendência das Empresas Incorporadas ao Patrimônio Nacional. Portanto, as glebas Missões e Chopin, que ficavam no Sudoeste do Paraná, agora patrimônio da União, passaram a ser administradas por esta superintendência. Este fator daria início a uma disputa litigiosa entre o Governo da União e o Estado do Paraná, que pretendia reaver esses territórios, visto que as mesmas lhe pertenciam conforme a Constituição Republicana. $^{21}$

No decorrer das questões judiciais, entre a União e o Estado, em maio de 1943, o presidente Getúlio Vargas, através do Decreto Lei Federal nº 12.417 cria a CANGO Colônia Agrícola Nacional General Osório. Neste decreto não ficou estipulado o limite, mas pretendia promover a ocupação do Sudoeste paranaense, a princípio nos limites das glebas Missões e Chopin. Tratava-se do projeto varguista da "marcha para o Oeste", buscando ocupar os "espaços vazios", sobretudo e estrategicamente neste caso, a região de fronteira com a Argentina. ${ }^{22}$

A CANGO foi projetada para assentar famílias nas terras que há muito foram desejadas pelo país vizinho. Brasil e Argentina haviam travado uma batalha diplomática sobre os limites territoriais do Sudoeste do Paraná. Mas as glebas do Sudoeste paranaense herdavam mais um fator no seu histórico litigioso. Ainda no final do século XIX, José Rupp obteve, por contrato de arrendamento de terras consideradas devolutas, o direito de explorador dos recursos de madeira e erva-mate sobre vários outros territórios dos estados de Santa Catarina e Paraná. No entanto,

\footnotetext{
${ }^{20}$ Odair Eduardo Geller, O Contestado entre Santa Catarina e Paraná: uma questão de limites nos limites da nação, (Curitiba: Prismas, 2016).

${ }^{21}$ Cf. Ruy Christovam Wachowicz, Paraná, Sudoeste: ocupação e colonização, (Curitiba: Ed. Vicentina, 1987).

${ }^{22}$ Ibid.
} 
estas foram transferidas por decreto para a Companhia Estrada de Ferro São PauloRio Grande. A Companhia requereu judicialmente o seu direito de posse, medida que lhe foi concedida e mais tarde cassada. Rupp entrou com uma ação indenizatória pelos direitos, que no seu entender, lhe cabiam ainda pela concessão do governo.

Na justiça, José Rupp obteve a penhora de várias glebas que haviam pertencido à São Paulo-Rio Grande, entre elas a Missões e Chopin. Vale lembrar que estas terras já haviam sido incorporadas à União em 1940. O Sudoeste do Paraná, com boa parte de seu território englobado por estas duas glebas, estava envolto em complexo emaranhado judicial quanto a posse das mesmas. Durante esta ação litigiosa que se alongava, Rupp vendeu seus "direitos" à CITLA - Clevelândia Industrial Territorial Ltda. Essa empresa colonizadora e de capital privado, tinha como proprietário majoritário Mário Fontana e era ligada ao antigo governador do Paraná Moisés Lupion. Em 1950, a CITLA obteve ilegalmente um título de domínio de terras lavrada em escritura pública no Tabelião de Oficio no Rio de Janeiro. ${ }^{23}$

Uma articulação extrajurídica fez da CITLA a "proprietária" das glebas Missões e Chopin. Ao mesmo tempo, a Superintendência, que negara acordos com Rupp, agora aceitava titular as posses para os novos "proprietários". A escritura que foi assinada em 1950 cingiu um total de 198 mil alqueires de terras, englobando a faixa de fronteira com a Argentina, a CANGO e inúmeras propriedades privadas, como lotes que já haviam sido comercializados com empresas imobiliárias de colonização.

Nas terras em litígio, se concentravam as sedes dos municípios de Francisco Beltrão, Santo Antônio do Sudoeste e Capanema. Municípios que passaram a receber as intensas levas de migrantes, sobretudo daquelas provindos das antigas colônias de imigração do Rio Grande do Sul e das mais recentes colônias de Santa Catarina. No período que corresponde de 1947 a 1956, mais de três mil famílias migraram para o Sudoeste para ocupar os lotes distribuídos pela CANGO, sendo em dados aproximados um total de 17 mil pessoas.

Devido a transação indevida, o tribunal de contas impediu a CITLA de comercializar e titular as terras, ao passo que a CANGO seguiu recebendo e

\footnotetext{
${ }^{23}$ Cf. Iria Zanoni Gomes, 1957, a Revolta dos Posseiros, (Curitiba: Criar Edições, 2005).
} 
assentando colonos das levas migratórias internas. No decorrer das ações litigiosas, a CITLA se instala na região, com sede em Francisco Beltrão, e passa a cobrar dos colonos já instalados o pagamento dos lotes de terra. Os até então posseiros, em boa parte até aceitariam fazer o pagamento para obter a propriedade, no entanto, o emaranhado judicial impedia a CITLA de escriturar as propriedades dos lotes.

Na prática, o grande problema enfrentado pela CITLA na região, era a CANGO. O grande estímulo promovido pela colônia agrícola, sendo que os lotes inicialmente eram distribuídos de forma gratuita e com importante infraestrutura de assentamento, promoveu vertiginosa e desenfreada ocupação. Como o decreto de criação da colônia não estipulava limites quanto a sua área, o Sudoeste continuou recebendo e assentando colonos, processo que ultrapassou os abordes sobre as glebas Missões e Chopin. As descrições constantes nos mapas estavam completamente erradas, pois foram baseadas em levantamentos topográficos realizados ainda em 1920, e que não correspondiam à realidade dos terrenos.

Os levantamentos preliminares realizados pela CITLA constataram que Missões era muito mais rica do que se imaginava, com mais de quatro milhões de pinheiros adultos industrializáveis. Várias quedas d'água, facilmente exploráveis, com incalculáveis árvores de erva-mate de exploração imediata e milhões de árvores de madeira de lei, predominando o cedro e a peroba. As milhares de toneladas de nó de pinho eram visadas como matéria prima para a indústria de plásticos. Diante de tamanha riqueza natural a CITLA construiu um campo de pouso para aeronaves de grande porte. Era preciso sobrevoar a área para mapear e verificar as melhores condições de ação, visto que a mata fechada dificultava o acesso por terra. ${ }^{24}$

Prevendo uma maior necessidade de segurança o Conselho de Segurança Nacional, exigiu a fixação em Francisco Beltrão de um destacamento do Exército. Aumentava a tensão na região, visto que os colonos não paravam de chegar e automaticamente tornavam-se posseiros. Vale lembrar que a ocupação ocorreu de forma ilegal e desordenada em função da insegurança fundiária causada pelos conflitos de terras entre Estado, a União e as companhias imobiliárias.

\footnotetext{
${ }^{24}$ Cf. Ruy Christovam Wachowicz, Paraná, Sudoeste: ocupação e colonização, (Curitiba: Ed. Vicentina, 1987).
} 
AS CORRENTES MIGRATÓRIAS E A ESTRATÉGIA DA DEVASTAÇÃO FLORESTAL COMO POSSE DA TERRA

Os sistematizados estudos de Wachowicz ${ }^{25}$ apontam que os ítalodescendentes gaúchos e catarinenses, somaram um percentual de $75 \%$ do contingente humano na ocupação da região Sudoeste paranaense. Apesar de predominarem como elemento étnico na ocupação das regiões aqui delimitadas, devemos lembrar da importância e reconhecida participação de outras etnias, bem como de outros estados, na ocupação da região. No entanto, independente das contribuições étnicas ou de diferentes regiões, o processo ocupacional, como vimos, seguiu aos moldes implementados pela CANGO, tornando todos pequenos agricultores com precária posse das terras, ou seja, posseiros.

Se analisarmos a história dos imigrantes italianos e ítalo-descendentes, encontraremos forte tendência relacionada a busca da propriedade da terra. As levas de imigrantes que se deslocaram para o Brasil no final do século XIX faziam parte de um projeto dos governos brasileiro e italiano. As condições antagônicas dos dois países permitiram esta trasladação de massas humanas, do velho para o novo mundo. As comunidades campesinas do norte da Itália encontravam-se em condições de subsistência, não possuíam acesso à propriedade da terra e a grande maioria dos camponeses era explorada como meeiro. Arrendavam as terras dos grandes proprietários pagando-lhe tributos, subsistindo em um modo de produção semifeudal.

Uma situação inversa se encontrava do outro lado do Atlântico, num país com dimensões continentais e que considerava ter suas terras "vazias". Tanto quanto não reconhecia as populações indígenas, também não reconhecia os africanos e seus descendentes como ocupantes do espaço, senão como mão de obra a ser explorada. A imigração de camponeses brancos europeus, portanto, era idealizada e idilizada. A visão hegemônica identificava as áreas "disponíveis" à ocupação, como estratégia de desenvolvimento econômico e de interesses geopolíticos fronteiriços ${ }^{26}$.

\footnotetext{
${ }^{25}$ Cf. Ruy Christovam Wachowicz, Paraná, Sudoeste: ocupação e colonização, (Curitiba: Ed. Vicentina, 1987).

${ }^{26}$ Cf. Rodrigo Kummer, "A pequena propriedade como mecanismo de desenvolvimento agrícola e industrial na política de colonização: aspectos da região Oeste de Santa Catarina" in Revista Semina, v. 16, n. 2 (2017), p. 80-100.
} 
Parte dos camponeses foi deslocada para a região Sudeste do Brasil, onde uns tornaram-se meeiros e outros assalariados da lavoura do café. Outra parte do excedente humano se direcionou para o Sul, com a finalidade de ocupar as acidentadas encostas da serra gaúcha. Em 1875, chegavam os primeiros camponeses na região. De início mais intenso, o fluxo de imigrantes se estendeu até 1914, interrompido pela eclosão da Primeira Guerra Mundial.

Já nas primeiras décadas da imigração, devido ao excesso populacional, a pressão demográfica provocou o fluxo migratório interno. "A densidade demográfica tornou os lotes pequenos e desencadeou-se o primeiro movimento migratório de caráter interno-espontâneo". ${ }^{27}$ Nas primeiras décadas do século XX, parte do excedente demográfico das colônias antigas de imigração foi absorvido na região do planalto gaúcho, onde algumas famílias de língua italiana migraram para os municípios do Alto Uruguai. Porém, neste período o maior fluxo migratório era absorvido pelas frentes de ocupação do Oeste catarinense.

A forte pressão demográfica dos colonos no Rio Grande do Sul promoveu o avanço de um processo de ocupação territorial que se estendeu, a seguir, por toda a região Norte do Estado chegando, em meados do século XX, ao Sul e Oeste catarinense, ao Paraná e, até mesmo, ultrapassando as fronteiras nacionais. ${ }^{28}$

Os italianos que abandonaram a Europa no final do Século XIX levavam consigo a tradição e o ideal da posse da terra, envolvendo o trabalho agrícola e familiar. Esta tradição predominou na ocupação da Serra Gaúcha, no Oeste catarinense e também no Sudoeste do Paraná. Como aponta Radin, "foi no trabalho da terra que, a princípio, a maioria dos imigrantes direcionados ao sul do Brasil buscaram realizar seu sonho na América. Além de representar a propriedade, a terra possibilitava-lhes o trabalho e este, por sua vez, a sobrevivência e a chance de vencer; coisas que no passado, nem sempre foram possíveis". ${ }^{29}$

\footnotetext{
${ }^{27}$ Ciro Mioranza; Vitalina Maria Frosi, Imigração italiana no nordeste do Rio Grande do Sul, (Porto Alegre: Educs, 1998$), 86$.

${ }^{28}$ Cf. Ismael Antônio Vannini, O sexo, o vinho e o diabo: demografia e sexualidade na colonização italiana do Rio Grande do Sul (1906-1970), (Passo Fundo: UPF Editora; Porto Alegre: EST, 2004).

${ }^{29}$ José Carlos Radin, Italianos e litalo-Brasileiros na Colonização do Oeste Catarinense, (Joaçaba: Edições UNOESC, 2001 ), 101.
} 
Os conflitos territoriais desencadeados pela Guerra do Contestado foram impactantes para o processo de colonização e ocupação oficial do Oeste catarinense, conforme aponta Delmir Valentini. ${ }^{30}$ No fim do conflito foram estabelecidos os limites entre os Estados, pelo acordo dividia-se praticamente ao meio o território contestado. Para Valentini, a definição dos limites em 1916, aumentou a preocupação do governo catarinense em relação às terras que passaram a lhe pertencer. A migração dos colonos ítalo-descendentes da serra gaúcha era uma estratégia imediata e essencial.

De ocupação posterior, o Oeste catarinense seguiu um modelo estrutural que se estendeu das antigas regiões de colonização italiana, do vizinho Estado do Rio Grande do Sul. A preservação do modelo estrutural do minifúndio policultor era feita com famílias numerosas que sustentavam o núcleo econômico na exploração do trabalho braçal. Estes padrões transplantados, logo cumpriram as metas do projeto, como ocorrera na região de origem, as terras devolutas e estratégicas estavam ocupadas e inseridas no contexto econômico.

Ao ingressar na década de 1940, tanto as colônias do Rio Grande do Sul como as de Santa Catarina, apresentavam uma nova carência de terra, o fluxo migratório agora se intensificara, além dos gaúchos, os catarinenses buscavam novas frentes agrícolas. Juntos, os ítalo-gaúchos e ítalo-catarinenses, ingressam em mais um fluxo migratório. Uma nova frente de ocupação se abria, era o contexto do governo varguista que imprimia a marcha para a ocupação do Oeste brasileiro, onde se inseria a região do Sudoeste paranaense. A intenção estratégica era de ocupar a fronteira com a Argentina. Em 1943, o governo federal através de um decreto do presidente Getúlio Vargas, criou uma colônia agrícola, como vimos, em terras que estavam em disputa judicial, destinada a colonizar parte das terras da região Sudoeste do Paraná.

A produção historiográfica que se deteve na temática da colonização do Sudoeste, com importante avanço nas duas últimas décadas, confirma as origens étnicas que contribuíram na colonização do Sudoeste, bem como o empreendimento oficial do governo: "a partir da década de 1940, dá início a ocupação intensiva da

\footnotetext{
${ }^{30}$ Delmir José Valentini, Da cidade santa a corte celeste: memórias de sertanejos e a Guerra do Contestado, (Caçador: Edições UNC, 2003)
} 
região com os migrantes gaúchos e catarinenses, descendentes de europeus que haviam colonizado as 'regiões antigas' do Rio Grande do Sul. Estabeleceram-se na região pela ocupação pura e simples de terras devolutas, mas principalmente pela iniciativa oficial, no caso, através da Colônia Agrícola Nacional General Osório CANGO". 31

De características semelhantes, o Sudoeste favoreceu a migração sem profundas alterações estruturais daquelas fundadas nas antigas colônias italianas do Rio Grande do Sul. As diretrizes seguiram o padrão da pequena propriedade policultora e de mão de obra familiar. Salvo as diferenças pela atuação da CANGO, no que diz respeito a forma de acesso à terra, o Sudoeste também representou uma extensão do modelo imigracionista constituído na Serra gaúcha e no Oeste catarinense.

Entre os pioneiros da historiografia do Sudoeste, Ruy Wachowicz, ao tratar da ocupação e colonização do Sudoeste, identifica as condições ideais para a migração de gaúchos e catarinenses para a região. Em minucioso trabalho de pesquisa, aponta o índice de contribuição de cada Estado na ocupação. Segundo o autor, "através do levantamento exaustivo dos registros de casamento nos cartórios de toda a região, foi possível obter a procedência da população desde 1900, até a data limite de 1975, ano por ano e município por município. Os dados apontam que os gaúchos contribuíram com o percentual de $43 \%$ do elemento humano na ocupação, enquanto que $28,8 \%$ foram catarinenses, o restante do percentual para paranaenses e de outras procedências". 32

De preponderância ítalo-descendentes, oriundos de antigas regiões colonizadoras, como vimos, os migrantes que ocuparam as glebas do Sudoeste, estimulados pela política da CANGO, trouxeram a cultura e o ideal da propriedade da terra, acalentado ainda no velho mundo. Este ideal preconizava a intervenção na floresta com a derrubada das matas para a produção de víveres. Processo implantado

\footnotetext{
31 Iria Zanoni Gomes, 1957, a Revolta dos Posseiros, (Curitiba: Criar Edições, 2005), 13.

${ }^{32}$ Ruy Christovam Wachowicz, Paraná, Sudoeste: ocupação e colonização, (Curitiba: Ed. Vicentina, 1987), 230.
} 
nas terras destinadas à colonização na serra gaúcha e Oeste catarinense, ideal transplantado para o Sudoeste do Paraná.

O maior estimulador da ação sobre a derrubada das florestas de araucárias do Sudoeste foi a insegurança quanto a legitimação da propriedade da terra. A devastação das matas, neste caso, foi acelerada pela indefinição legal e da titulação dos lotes. O colono que fora assentado pela CANGO, como vimos, não poderia receber o título de proprietário. A partir dessa conjuntura os colonos lançaram mão da estratégia de demarcar a ocupação e reivindicar a posse por meio da derrubada da floresta. De forma consciente, os colonos entendiam como um uti possidetis juris, salvas as proporções do mesmo em caráter histórico, que onde haveria o desmatamento e produção de viveres, seria seu, pelo menos em direito precário.

Outro fator importante para compreender o processo ocupacional do território do Sudoeste paranaense foi a especificidade do decreto de criação da CANGO que estipulava um limite mínimo e não delimitava sua extensão máxima: “a área a ser demarcada não será inferior a 300.000 hectares". ${ }^{33}$ Isso dificultou o controle da distribuição dos lotes, visto a imagem de uma área "sem limites" e de fácil acesso. Nesse sentido, muitos colonos acudiram à região e ocupavam diretamente os lotes, sem contato com CANGO e sem a titulação, o caracterizava uma posse precária. Não se constituíam como propriedades privadas registradas e reconhecidas pelo Estado, mas espaços ocupados à sua revelia. Essa urgência de garantir o reconhecimento da posse acelerava o desmatamento. Nesse contexto, a CANGO não tinha o controle claro sobre as áreas já ocupadas e as áreas por ocupar, gerando um ambiente de desorganização e instabilidade jurídica.

A proposta deste ensaio não é abordar o desfecho litigioso da questão fundiária do Sudoeste, mas perceber que a estratégia de posse adotada pelos colonos foi definitiva e determinante a seu favor. Após um levante armado no ano de 1957 e a intervenção do governo federal, as terras foram desapropriadas e os lotes titulados, seguindo os limites da posse que as famílias haviam atingido. A situação caótica vivida naqueles anos, com o avanço dos posseiros sobre o território para limpar a terra, seja para o cultivo como para delimitar a posse, resultou na devastação indiscriminada da floresta nativa. Os dados apresentados por Ruy Wachowicz impressionam ao apontar

${ }^{33}$ República Federativa do Brasil, Decreto nº 12.417, de 12 de maio de 1943. 
que apenas 20 e no máximo 30\% das árvores foram aproveitadas. O restante, daquela que fora a maior floresta de araucárias do planeta, transformou-se em cinzas. ${ }^{34}$

Liga-se a isso o estudo de caso de Bublitz ${ }^{35}$ sobre as transformações causadas as florestas do vale do Rio dos Sinos pelos imigrantes alemães. A autora reitera a existência de um processo de impactos ambientais associado à ação de movimentação e reprodução dos espaços coloniais: "toda essa obsessão pela mata virgem traduzia-se, porém, em um ímpeto predatório sem precedentes, mesmo que os colonos não tivessem consciência disso. Boa parte deles mantinha-se em constante migração rumo à fronteira verde, a fim de conseguir novas terras, já que as antigas haviam se tornado pequenas demais para o grande número de filhos gerados no Brasil, e degradadas demais, a ponto de já não fornecerem alimentos como antes". ${ }^{36}$

O fato da densidade da vegetação, realçando o território como inóspito a ocupação humana, não abalou o ideário desenvolvimentista dos colonos, pois apesar dessas dificuldades preliminares daquela vegetação seria extraído o primeiro capital. Árvores grandiosas, vegetação densa e literalmente fechada eram aspectos que engendravam em uma dispendiosa atividade, derrubar aquela mata que se fazia tão imponente e fazer brotar daquele jugo a riqueza tão sonhada. Derrubar a mata significava obter o domínio efetivo sobre a terra, além de conseguir madeira tábuas - para construções variadas e algum dinheiro com possíveis vendas. Segundo Leo Weibel, "uma família pioneira começa o ciclo cultural comprando a terra numa área de mata desabitada. Em seguida, derruba e queima a floresta, à maneira dos índios; planta milho, feijão preto e mandioca". 37 Da mesma forma assevera Bublitz, “[...] enquanto se mantinha vicejante e robusta, a mata era considerada uma prisão. O colono, muitas vezes, sentia-se um escravo da floresta. Era preciso trabalhar com afinco, em uma luta sem tréguas, para derrubar a vegetação e impor o domínio sobre a natureza. Floresta derrubada era um sinônimo de civilização, de progresso". ${ }^{38}$

É pertinente considerar que o processo de colonização em si gerou significativos impactos ambientais. Nas áreas de colonização do Rio Grande do Sul, o esgotamento do solo e dos demais recursos influenciou a busca por novas terras a serem exploradas. O modelo ideológico de desenvolvimento considerava a fartura de terras como condição de expansão populacional.

\footnotetext{
${ }^{34}$ Cf. Ruy Christovam Wachowicz, Paraná, Sudoeste: ocupação e colonização, (Curitiba: Ed. Vicentina, 1987).

35 Juliana Bublitz, "Forasteiros na floresta subtropical: notas para uma história ambiental da colonização alemã no Rio Grande do Sul" in Ambiente \& Sociedade, 2, (2008), p. 323-340.

${ }^{36}$ Ibid, p. 331.

${ }^{37}$ Leo Waibel, "Princípios da colonização europeia no Sul do Brasil" in Revista Brasileira de Geografia, 2, (1949), 172.

${ }^{38}$ Ibid, p. 327.
} 
Contudo, essas dinâmicas econômicas e o modus operandi de intervenção verticalizada no ambiente, drenando todos os recursos com urgência e predação, potencializou os impactos ambientais de forma massiva.

Os fatores do contexto histórico incitaram a ação dos posseiros sobre o ambiente natural, na medida em que as necessidades, as estratégias e a tradição cultural fizeram-se presentes. A tradição cultural aqui se entende como uma herança do elemento colonizador e descendente. O ideal da propriedade do lote, trazido pelo imigrante europeu, onde as terras do novo mundo precisavam ser "domadas" para gerar frutos promovia, sobretudo, a intervenção direta do homem no ambiente. Intervenção esta que se iniciava no desmatamento para gerar a produção de víveres e a capitalização do núcleo familiar. Assim fora nas antigas colônias da Serra gaúcha e se estendeu para as frentes de colonização do Oeste catarinense e Sudoeste do Paraná.

\section{CONSIDERAÇÕES FINAIS}

As problematizações e reflexões em relação aos fatores que definiram a ação colonizadora do Sudoeste paranaense nos apresentam um conjunto de elementos que explicitam o histórico ambiental. A ação humana sobre o bioma foi o resultado do contexto histórico, na medida que as forças - entre interesses, estratégias e necessidades, culminaram no processo de acelerada intervenção sobre o ambiente.

A carência de terras nas antigas colônias concentrava um excedente humano que almejava a propriedade do minifúndio policultor. A nova frente colonizadora, muito propagada, e, como vimos, estimulada pela estratégica política de ocupação de espaços considerados "vazios", desencadeou um vertiginoso processo migratório para a região em questão. Aqui se registra a expansão de um projeto iniciado ainda na segunda metade do século XIX, onde imigrantes europeus ocuparam importantes regiões do Rio Grande do Sul no projeto estatal de imigração. Salvas as proporções, as correntes migratórias internas que se deslocaram no século seguinte, para o Oeste catarinense e Sudoeste do Paraná, além de seus interesses, cumpriam a estratégia ocupação oficial do espaço e da exploração econômica nos moldes capitalistas. O dito 
vazio tornou-se, segundo o discurso hegemônico, um espaço de "progresso". O preço foi pago primeiro pelas populações indígenas e caboclas. Depois pelo meio ambiente.

Junto ao elemento humano, implementou-se a cultura do desmatamento civilizador, associado ao interesse de capitalização da pequena propriedade de economia familiar. É imperativo advertir que naquele momento as forças governamentais imprimiam forte exigência quanto ao caráter produtor dos núcleos; as frentes de expansão imprimiam um sentido de produção imediato.

Mas o fator de maior relevância, que se observa na ocupação do Sudoeste paranaense e na ação sobre o ambiente é um processo que difere profundamente das outras experiências colonizadoras. Na maioria dos outros exemplos, as matas foram devastadas, sendo a madeira industrializada para o comércio, importante recurso extrativista das frentes pioneiras de colonização. Em sentido contrário, a jurisprudência fundiária e toda a instabilidade gerada quanto a titulação dos lotes, provocou acelerado desmatamento como elemento demarcador da posse fundiária. E o fogo transformou-se no aliado do homem sudoestino ao transformar as matas em cinzas, "limpando" a terra e garantindo a posse.

\section{REFERENCIAS}

Arlene Renk, A luta da erva: um ofício étnico no Oeste Catarinense, (2. ed. rev. Chapecó: Argos, 2006).

Cf. Adelar Heinsfeld, A questão de Palmas entre Brasil e Argentina, (Joaçaba: Ed. UNOESC, 1999).

Cf. Donald Worster, "Para Fazer História ambiental" in Estudos Históricos, 8, (1991), p. 198-215.

Cf. Iria Zanoni Gomes, 1957, a Revolta dos Posseiros, (Curitiba: Criar Edições, 2005).

Cf. Ismael Antônio Vannini, O sexo, o vinho e o diabo: demografia e sexualidade na colonização italiana do Rio Grande do Sul (1906-1970), (Passo Fundo: UPF Editora; Porto Alegre: EST, 2004).

Cf. José Augusto Pádua, "As bases teóricas da História Ambiental", in Estudos Avançados, 68, (2010), p. 81-101. 
Cf. José Lúcio da Silva Machado, O Sertão e o Cativo. Escravidão e Pastoreio: Os campos de Palmas-Paraná 1859-1888, (Porto Alegre: Coleção Malungo-FCM Editora, 2015).

Cf. Rodrigo Kummer, "A pequena propriedade como mecanismo de desenvolvimento agrícola e industrial na política de colonização: aspectos da região Oeste de Santa Catarina" in Revista Semina, v. 16, n. 2 (2017), p. 80-100.

Cf. Ruy Christovam Wachowicz, Paraná, Sudoeste: ocupação e colonização, (Curitiba: Ed. Vicentina, 1987).

Cf. Wilmar da Rocha D’Angelis, "Para uma história dos índios no Oeste catarinense", Cadernos do CEOM: 20 anos de memórias e histórias no oeste de Santa Catarina, ano 19, n. 23, (2006). p. 265-346.

Ciro Mioranza; Vitalina Maria Frosi, Imigração italiana no nordeste do Rio Grande do Sul, (Porto Alegre: Educs, 1998), 86.

Delmir José Valentini, Da cidade santa a corte celeste: memórias de sertanejos e a Guerra do Contestado, (Caçador: Edições UNC, 2003).

Iria Zanoni Gomes, 1957, a Revolta dos Posseiros, (Curitiba: Criar Edições, 2005), 13.

José Carlos Radin, Italianos e Íitalo-Brasileiros na Colonização do Oeste Catarinense, (Joaçaba: Edições UNOESC, 2001), 101.

Juliana Bublitz, "Forasteiros na floresta subtropical: notas para uma história ambiental da colonização alemã no Rio Grande do Sul" in Ambiente E Sociedade, 2, (2008), p. 323340 .

Leo Waibel, "Princípios da colonização europeia no Sul do Brasil" in Revista Brasileira de Geografia, 2, (1949), 172.

Odair Eduardo Geller, O Contestado entre Santa Catarina e Paraná: uma questão de limites nos limites da nação, (Curitiba: Prismas, 2016).

República Federativa do Brasil, Decreto nº 12.417, de 12 de maio de 1943.

Ruy Christovam Wachowicz, Paraná, Sudoeste: ocupação e colonização, (Curitiba: Ed. Vicentina, 1987), 230.

Vera Lúcia Fregonese, "Experiência de colonização: Colônia Militar do Chopin", in História: construção de múltiplas interfaces, Carlos Antônio Bonamigo (Francisco Beltrão: Grafisul, 2006), 195.

Wilmar da Rocha D’Angelis, "Para uma história dos índios no Oeste catarinense", Cadernos do CEOM: 20 anos de memórias e histórias no oeste de Santa Catarina, ano 19, n. 23, (2006). p. 265-346, 293. 


\title{
Southwestern Paraná: Deforestation as Land Ownership Strategy (1940-1960)
}

\begin{abstract}
This paper presents an approach on the process of occupation and colonization of Southwestern Paraná. Occupied by the displacement of internal migration flows, which occurred between 1940 and 1960, the region that concentrated the largest Araucaria forest on the planet was profoundly transformed by government action, by real estate companies and the squatter settlers. Litigious actions between the state government and Union prevented the drafting of the deed of lots and the settlers became squatters. Deforestation became the settlers' strategy to delimit their possession. As a result, studies show that $80 \%$ of the vast pine forest turned into ashes. Thus, the Environmental History of Southwestern Paraná has direct elements of government policy and human action related to land ownership.
\end{abstract}

Keywords: Southwestern Paraná; Deforestation; Environmental History. 